\title{
EVALUATION OF ADMISSION TIME HYPERGLYCAEMIA IN ACUTE CORONARY SYNDROME PATIENTS
}

Vinit Chaudhary'1, Swati Aundhakar², Shivaraj Afzalpurkar³, Piyush Prajapati, Shakuntala Prajapati5 , Aken Desai', Saurabh Gandhi ${ }^{7}$, Omkar Patil

${ }^{1}$ Lecturer, Department of Medicine, Krishna Institute of Medical Sciences, Karad.

2 Professor and HOD, Department of Medicine, Krishna Institute of Medical Sciences, Karad.

${ }^{3}$ Resident, Department of Medicine, Krishna Institute of Medical Sciences, Karad.

${ }^{4}$ Resident, Department of Medicine, Krishna Institute of Medical Sciences, Karad.

${ }^{5}$ Consultant, Department of Pathology, SMC, Mehsana.

${ }^{6}$ Resident, Department of Medicine, Krishna Institute of Medical Sciences, Karad.

${ }^{7}$ Resident, Department of Medicine, Krishna Institute of Medical Sciences, Karad.

${ }^{8}$ Resident, Department of Medicine, Krishna Institute of Medical Sciences, Karad.

\section{ABSTRACT}

\section{BACKGROUND}

Hyperglycaemia, in both diabetic and nondiabetic patients, has a significant negative impact on the morbidity and mortality of patients presenting with an Acute Myocardial Infarction (AMI). Contemporary evidence indicates that persistent hyperglycaemia after initial hospital admission continues to exert negative effects on AMI patients. There have been a number of studies demonstrating the benefit of tight glucose control in patients presenting with AMI, but a lack of convincing clinical data has led to loose guidelines and poor implementation of glucose targets for this group of patients.

\section{MATERIALS AND METHODS}

100 patients who came with Acute Coronary Syndrome who had admission time hyperglycaemia during October 2012 to September 2014 were studied in this study. Hyperglycaemia was defined in the current study as random blood glucose at admission more than $200 \mathrm{mg} / \mathrm{dL}$. We studied patients of more than 18 years of age who were diagnosed as Acute Coronary Syndrome- ST Segment Elevation Myocardial Infarction (STEMI), Non-ST Segment Elevation Myocardial Infarction (NSTEMI) and Unstable Angina (UA).

\section{RESULTS}

Mean age for diabetic patients was 57.40 years and for non-diabetic patients was 56.09 years. Males were more susceptible to develop ACS in both the groups. Incidence of STEMI and NSTEMI was more in diabetics than non-diabetics. Incidence of Unstable Angina was more in non-diabetics than diabetics.

\section{CONCLUSION}

Incidence of complications is higher (surprisingly) in non-diabetics as compared to diabetics. Incidence of death is much higher in diabetics as compared to non-diabetics with stress hyperglycaemia (on admission). Hence, blood glucose level and HbA1c levels should be routinely measured in every patient with Acute Coronary Syndrome.

\section{KEYWORDS}

Hyperglycaemia, Diabetes Mellitus, Arrhythmia, Cardiogenic Shock, Cardiac Arrest.

HOW TO CITE THIS ARTICLE: Chaudhary V, Aundhakar S, Afzalpurkar S, et al. Evaluation of admission time hyperglycaemia in acute coronary syndrome patients. J. Evolution Med. Dent. Sci. 2017;6(20):1639-1642, DOI: 10.14260/Jemds/2017/359

\section{BACKGROUND}

High admission blood glucose levels after acute coronary events are common and are associated with an increased risk of death in subjects with and without diabetes. ${ }^{1}$

Elevated admission glucose levels in non-diabetic patients with ACS are independently associated with larger infarct sizes and higher long-term mortality rates when compared with patients with normal glucose levels. Glycometabolic state at hospital admission is an important risk marker for long-term mortality in patients with acute coronary syndrome.

Financial or Other, Competing Interest: None.

Submission 30-01-2017, Peer Review 23-02-2017,

Acceptance 01-03-2017, Published 09-03-2017.

Corresponding Author:

Dr. Piyush Prajapati,

IHR Hostel, Krishna Institute of Medical Sciences,

Karad, Maharashtra.

E-mail: prajapatipiyush786@gmail.com

DOI: $10.14260 /$ jemds $/ 2017 / 359$

\section{(c) $(1)$}

Stress plays an important role in the regulation of insulin secretion. A variety of common clinical illnesses lead to stress, which are commonly associated with increased blood glucose levels. Acute insulin response is inhibited by catecholamines by alpha adrenergic receptor stimulation. The stress effect is probably an index of sympathetic nervous system overactivity. Epinephrine blocks insulin secretion, stimulates glucagon release, activates glycogen, ${ }^{2}$ breakdown and impairs insulin action in target tissues such that capacity to dispose off an exogenous glucose load is impaired.

Several studies have shown that abnormally inhibited acute insulin secretion during stress can be improved by alpha blockage and have supported the concept that inhibition of insulin secretion during stress is attributed to overactivity of the adrenergic nerves. ${ }^{3}$

The reaction to stress operates primarily through two basic endocrine mechanisms, one relating to the adrenal medulla and the other to the adrenal cortex. ${ }^{4}$ The adrenal medulla combined with other components of the sympathetic nervous system serves as an "alarm" mechanism to mobilise 
glucose as well as fatty acids and lactic acid. The means by which the rise in glucose occurs is by -

1. Increased glycogenolysis in the liver.

2. Direct inhibition of glucose uptake by the muscle.

3. An inhibitory effect of epinephrine upon pancreatic insulin release lessening any rise in serum insulin.

The second principal endocrine mechanism of sustaining or raising blood glucose is through stimulation of pituitary adrenocortical axis, clinical studies are not clear in delineating how much or what type of stress gives this corticoid response. 4

One third of all individuals with hyperglycaemia admitted to an urban general hospital do not have a previous diagnosis of diabetes in these patients. Hyperglycaemia is a risk factor for adverse outcomes during acute illness like acute myocardial infarction. Patients with stress hyperglycaemia were at increased risk of Congestive Heart Failure and cardiogenic shock when compared to patients with diabetes mellitus. Stress hyperglycaemia after myocardial injury is associated with an increased risk of in-hospital mortality. During acute myocardial insult, hyperglycaemia is associated with increased levels of inflammatory markers and enhanced expression of cytotoxic T-cells. ${ }^{5}$ An increased inflammatory immune process leads to poor cardiac outcome, especially in acute myocardial infarction patients. So stress hyperglycaemia amplifies inflammatory immune reaction and worsens functional cardiac outcome. The relation between infarct size and plasma glucose concentration confirms that stress hyperglycaemia is a real phenomenon in patients with acute myocardial infarction, which leads to poor patient outcome. Larger infarctions results in more pronounced sympathetic nervous system activation and catecholamine secretion that leads to hyperglycaemia on one hand and higher mortality on the other.6,7

G A Oswald et al in 1986 showed a correlation between plasma concentrations of adrenaline in the early stages of the infarction and the size of the infarct. Hyperglycaemia measured on admission in most non-diabetic patients with acute MI is determined both by the extent of infarction, mainly through the secretion of adrenaline and through secretion of other stress hormones that are independent of infarct size. ${ }^{7}$ In experimental MI, it has been suggested that the stimulus to adrenaline release is reflex arising from receptors at the site and boundary of the infarct. The relation of plasma concentration of adrenaline early in the course of infarction to infarct size in the patients studied is compatible with a similar mechanism existing in man. ${ }^{8}$

\section{MATERIALS AND METHODS}

We Studied Patients of more than 18 Years of Age who were Diagnosed as Acute Coronary Syndrome -

- $\quad$ ST Segment Elevation Myocardial Infarction (STEMI).

- Non-ST Segment Elevation Myocardial Infarction (NSTEMI).

- Unstable Angina (UA).

With their Supportive Evidences from -

- Clinical history.

- Examination.

- ECG changes.

- Biochemical markers.

\section{Inclusion Criteria}

Patients having age above 18 years with features of Acute Coronary Syndrome.

\section{Exclusion Criteria}

- Age less than 18 years.

- Non-cardiac chest pain patients.

\section{Study Design}

100 patients presenting with Acute Coronary Syndrome who had admission time hyperglycaemia and who fulfilled inclusion/exclusion criteria were enrolled for the study.

\section{Data Analysis}

Hyperglycaemia was defined in the current study as random blood glucose at admission more than $200 \mathrm{mg} / \mathrm{dL}$.(9) Patients were stratified based on their history of diabetes mellitus and the blood glucose levels at the admission.

- Admission time hyperglycaemia with diabetes mellitus.

- Admission time hyperglycaemia without diabetes mellitus.

\section{Instruments, Materials Required and Used -}

1. ECG.

2. Blood Sugar Level by GOD-POD method. Semi Auto Analyser (ERBA CHEM-5 PLUS) Semi Auto Analyser (ERBA CHEM-7 PLUS).

3. Troponin I by Ami-check Kit.

\section{RESULTS}

\begin{tabular}{|c|c|c|c|c|}
\hline \multirow{2}{*}{$\begin{array}{l}\text { Age in } \\
\text { Years }\end{array}$} & \multicolumn{2}{|c|}{ Diabetic Patients } & \multicolumn{2}{|c|}{ Non-Diabetic Patients } \\
\hline & Male & Female & Male & Female \\
\hline$<30$ & 1 & 0 & 0 & 0 \\
\hline $31-40$ & 2 & 0 & 4 & 1 \\
\hline $41-50$ & 6 & 4 & 6 & 4 \\
\hline $51-60$ & 8 & 6 & 9 & 5 \\
\hline $61-70$ & 10 & 4 & 7 & 6 \\
\hline $71-80$ & 6 & 1 & 3 & 2 \\
\hline$>80$ & 1 & 1 & 2 & 1 \\
\hline Total & $34(68 \%)$ & $16(32 \%)$ & $31(62 \%)$ & $19(38 \%)$ \\
\hline Mean \pm SD & $\begin{array}{c}58.52 \pm \\
9.87\end{array}$ & $\begin{array}{c}56.29 \pm \\
10.04\end{array}$ & $\begin{array}{c}56.61 \pm \\
11.25\end{array}$ & $\begin{array}{c}55.58 \pm \\
10.59\end{array}$ \\
\hline Tabl & $\begin{array}{l}\text { ge and } \\
\text { Acute Col } \\
\text { atients a }\end{array}$ & $\begin{array}{l}\text { Wise Di } \\
\text { lary Sync } \\
\text { Non-Dia }\end{array}$ & $\begin{array}{l}\text { bution in } \\
\text { me in Dia } \\
\text { ic Patien }\end{array}$ & $\begin{array}{l}\text { atients } \\
\text { etic }\end{array}$ \\
\hline
\end{tabular}

\begin{tabular}{|c|c|c|}
\hline \multirow{2}{*}{ Diagnosis } & $\begin{array}{c}\text { Diabetic } \\
\text { Patients }\end{array}$ & $\begin{array}{c}\text { Non-Diabetic } \\
\text { Patients }\end{array}$ \\
\cline { 2 - 3 } & No. (\%) & No. (\%) \\
\hline NSTEMI & $9(18 \%)$ & $6(12 \%)$ \\
\hline STEMI & $23(46 \%)$ & $15(30 \%)$ \\
\hline UA & $18(36 \%)$ & $29(58 \%)$ \\
\hline Total & $\mathbf{5 0}$ & $\mathbf{5 0}$ \\
\hline \multicolumn{2}{|c|}{$\begin{array}{r}\text { Table 2. Association between Diagnosis } \\
\text { and Diabetic and Non-Diabetic Patients }\end{array}$} \\
\hline
\end{tabular}

\begin{tabular}{|c|c|c|}
\hline \multirow[t]{2}{*}{ Complications } & $\begin{array}{l}\text { Diabetic } \\
\text { Patients }\end{array}$ & $\begin{array}{l}\text { Non-Diabetic } \\
\text { Patients }\end{array}$ \\
\hline & No. (\%) & No. (\%) \\
\hline Arrhythmia & $9(18 \%)$ & $20(40 \%)$ \\
\hline Shock (Cardiogenic) & $13(26 \%)$ & $16(32 \%)$ \\
\hline Cardiac Arrest & $12(24 \%)$ & $4(8 \%)$ \\
\hline Acute LVF & $18(36 \%)$ & $18(36 \%)$ \\
\hline Death & $11(22 \%)$ & $4(8 \%)$ \\
\hline \multicolumn{3}{|c|}{$\begin{array}{l}\text { Table 3. Association between Complications } \\
\text { and Diabetic and Non-Diabetic Patients }\end{array}$} \\
\hline
\end{tabular}

Value of $\chi^{2}=11.411, p=0.0223$, significant. 
By applying Chi-Square test, there is significant association between complications and diabetic and nondiabetic patients $(\mathrm{p}=0.0223)$.

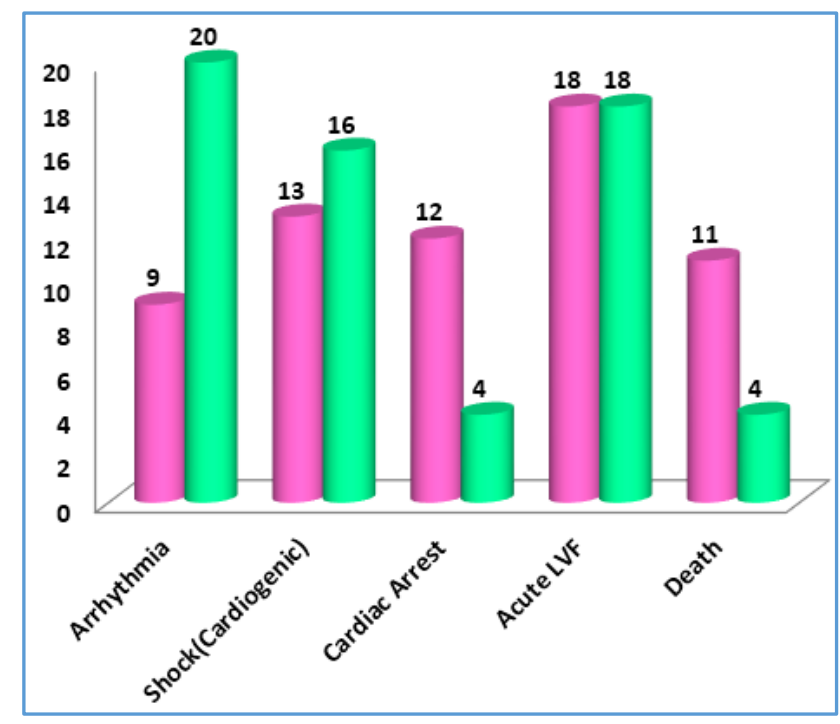

\begin{tabular}{|c|c|c|}
\hline \multirow{2}{*}{$\begin{array}{c}\text { Final } \\
\text { Outcome }\end{array}$} & $\begin{array}{l}\text { Diabetic } \\
\text { Patients }\end{array}$ & $\begin{array}{c}\text { Non-Diabetic } \\
\text { Patients }\end{array}$ \\
\hline & No. (\%) & No. (\%) \\
\hline Recovered & $39(78 \%)$ & $46(92 \%)$ \\
\hline Death & $11(22 \%)$ & $4(8 \%)$ \\
\hline Total & 50 & 50 \\
\hline
\end{tabular}

Value of $\chi^{2}=2.824, p=0.0929$, significant.

By applying Chi-Square test, there is significant association between final outcome (recovered and death) and diabetic and non-diabetic patients $(p=0.0929)$.

\section{DISCUSSION}

Hyperglycaemia at the time of hospital admission predicts increased mortality in patients with Acute Coronary Syndromes (ACS) including ST-Segment Elevation Myocardial Infarction (STEMI),(10-15) revascularisation procedures such as thrombolysis or Percutaneous Coronary Intervention (PCI),(16-19) and other critical illnesses.(20-22) The relationship between blood glucose and mortality appears linear with escalating risk associated with increasing blood glucose levels and is independent of a diagnosis of diabetes.(23)

There are three main hypotheses as to why hyperglycaemia portends higher mortality in acutely ill patients. First elevated blood glucose can be a physiologic response to hormones, such as epinephrine or cortisol that are released under high systemic stress and hence may indicate greater overall illness severity.(24) For example, those subjects with larger areas of myocardial ischaemia and more impaired left ventricular function may have stronger sympathetic activation leading to higher glucose levels. Second, hyperglycaemia may be an indicator of systemic and organ-specific metabolic dysregulation, especially impaired insulin signalling. In this regard, insulin resistance causes not only hyperglycaemia but also may lead to a reduction in energy production in the heart and other organs producing a lower tolerance to hypoperfusion. In a similar vein, reduced insulin signalling may increase vulnerability to ischaemic injury, because downstream molecules in the insulin signalling cascade have well-established cytoprotective effects and these are lost when insulin-signalling pathways are disrupted. $(25,26)$ Third, acute hyperglycaemia is implicated in the activation of other pathologic processes that could contribute to cellular and tissue injury, such as increasing free radical formation and oxidative stress, inducing of a prothrombotic state and worsening endothelial function. 27 29)

- 100 patients who came with Acute Coronary Syndrome who had admission time hyperglycaemia during October 2012 to September 2014 were studied in this study.

- 50 patients who were non-diabetic, but had admission time hyperglycaemia $>200 \mathrm{mg} / \mathrm{dL}$ with $\mathrm{HbA} 1 \mathrm{c}<6.5 \%$ were labelled as stress hyperglycaemia. Their blood sugar came to normal levels after $2^{\text {nd }} / 3^{\text {rd }}$ day.

- 4 patients who were diabetic, but had admission time hyperglycaemia $>200 \mathrm{mg} / \mathrm{dL}$ with $\mathrm{HbA1c}<6.5 \%$. Their blood sugar also came to normal levels after $2^{\text {nd }} / 3^{\text {rd }}$ day. (i.e. diabetics with good glycaemic control).

- Remaining 46 patients who were diabetic, but had admission time hyperglycaemia $>200 \mathrm{mg} / \mathrm{dL}$ with HbA1c $>6.5 \%$, they had uncontrolled sugar levels (i.e. diabetics with poor glycaemic control).

- Mean age for diabetic patients was 57.40 years and for non-diabetic patients was 56.09 years.

- Males were more susceptible to develop ACS in both the groups.

- Incidence of STEMI and NSTEMI was more in diabetics than non-diabetics.

- Incidence of Unstable Angina was more in non-diabetics than diabetics.

- Complications like Arrhythmia and Cardiogenic Shock were seen more in non-diabetics than in diabetics. Cardiac arrests and Death were seen more in diabetics than non-diabetics. Acute LVF was equally common in both diabetics and non-diabetics.

- In diabetics 28/50 (56\%) patients developed complications and in non-diabetics 34/50 (68\%) patients developed complications.

- Deaths occurred in 15 patients. Out of it, 11 (22\%) were diabetic and 4 (8\%) were non-diabetic.

- Deaths were more due to Cardiogenic shock, Cardiac arrest and Acute LVF in diabetics than non-diabetics.

- 4 patients who were diabetic with controlled HbA1c i.e. HbA1c $<6.5 \%$, but had admission time hyperglycaemia developed arrhythmias.

\section{CONCLUSION}

Incidence of complications is higher (Surprisingly) in nondiabetics as compared to diabetics. Incidence of death is much higher in diabetics as compared to non-diabetics with stress hyperglycaemia (on admission). Hence, blood glucose level and $\mathrm{HbA} 1 \mathrm{c}$ levels should be routinely measured in every patient with Acute Coronary Syndrome.

\section{REFERENCES}

[1] Mani VE, John M, Calton R. Impact of HbA1c on acute cardiac states. Journal of Association of Physician India. 2011;59:1-3. 
[2] Apple FS, Falahati A, Paulsen PR, et al. Improved detection of minor ischemic myocardial injury with measurement of serum cardiac troponin I. Clin Chem 1997;43(11):2047-51.

[3] Mair J, Moeandell D, Genser N, et al. Equivalent early sensitivity of myoglobin, creatinine kinase MB mass, Creatinine kinase isoform ratios and cardiac Troponins I \& T for acute myocardial infarction. Clin Chem 1995;41:1266-72.

[4] Husband DJ, Alberti KG, Julian DG. "Stress" hyperglycemia during acute myocardial infarction: an indicator of pre-existing diabetes? Lancet 1983;322(8343):179-81.

[5] Ceriello A, Toboga C, Tonutti L, et al. Evidence for an independent and cumulative effect of post prandial hypertriglyceridaemia and hyperglycemia on endothelial dysfunction and oxidative stress generation: effects of short and long term simvastatin treatment. Circulation 2002;106(10):1211-8.

[6] Karlsberg RP, Cryer PE, Roberts R. Serial plasma catecholamine response early in the course of clinical acute myocardial infarction: relationship to infarct extent and mortality. Am Heart J 1981;102(1):24-9.

[7] Bailey RR, Abernethy MH, Beaven DW. Adernocortical response to the stress of an acute myocardial infarction. Lancet 1967;289(7497):970-3.

[8] Ceriello A. Acute hyperglycemia and oxidative stress generation. Diabetes Medicine 1997;14(Suppl 3):S459.

[9] American Diabetes Association. Diagnosis and classification of diabetes mellitus. Diabetes care 2014;37(Suppl 1):S81-S90.

[10] Timmer JR, Hoekstra M, Nijsten MW, et al. Prognostic value of admission glycosylated hemoglobin and glucose in nondiabetic patients with ST-segmentelevation myocardial infarction treated with percutaneous coronary intervention. Circulation 2011;124(6):704-11.

[11] Capes SE, Hunt D, Malmberg K, et al. Stress hyperglycaemia and increased risk of death after myocardial infarction in patients with and without diabetes: a systematic overview. Lancet 2000;355(9206):773-8.

[12] Angeli F, Verdecchia P, Karthikeyan G, et al. New-onset hyperglycemia and acute coronary syndrome: a systematic overview and meta-analysis. Curr Diabetes Rev 2010;6(2):102-10.

[13] Goyal A, Mahaffey KW, Garg J, et al. Prognostic significance of the change in glucose level in the first $24 \mathrm{~h}$ after acute myocardial infarction: results from the CARDINAL study. Eur Heart J 2006;27(11):128997.

[14] Malmberg K, Norhammar A, Wedel H, et al. Glycometabolic state at admission: important risk marker of mortality in conventionally treated patients with diabetes mellitus and acute myocardial infarction: long-term results from the Diabetes and Insulin-Glucose Infusion in Acute Myocardial Infarction (DIGAMI) study. Circulation 1999;99(20):2626-32.
[15] Kosiborod M, Rathore SS, Inzucchi SE, et al. Admission glucose and mortality in elderly patients hospitalized with acute myocardial infarction: implications for patients with and without recognized diabetes. Circulation 2005;111(23):3078-86.

[16] Wahab NN, Cowden EA, Pearce NJ, et al. Is blood glucose an independent predictor of mortality in acute myocardial infarction in the thrombolytic era? J Am Coll Cardiol 2002;40(10):1748-54.

[17] Ekmekci A, Cicek G, Uluganyan M, et al. Admission hyperglycemia predicts inhospital mortality and major adverse cardiac events after primary percutaneous coronary intervention in patients without diabetes mellitus. Angiology 2014;65(2):154-9.

[18] Ishihara M, Kojima S, Sakamoto $T$, et al. Acute hyperglycemia is associated with adverse outcome after acute myocardial infarction in the coronary intervention era. Am Heart J 2005;150(4):814-20.

[19] Planer D, Witzenbichler B, Guagliumi G, et al. Impact of hyperglycemia in patients with ST-segment elevation myocardial infarction undergoing percutaneous coronary intervention: the HORIZONS-AMI trial. Int J Cardiol 2013;167(6):2572-9.

[20] Falciglia M, Freyberg RW, Almenoff PL, et al. Hyperglycemia-related mortality in critically ill patients varies with admission diagnosis. Crit Care Med 2009;37(12):3001-9.

[21] Egi M, Bellomo R, Stachowski E, et al. Blood glucose concentration and outcome of critical illness: the impact of diabetes. Crit Care Med 2008;36(8):2249-55.

[22] Whitcomb BW, Pradhan EK, Pittas AG, et al. Impact of admission hyperglycemia on hospital mortality in various intensive care unit populations. Crit Care Med 2005;33(12):2772-7.

[23] Foo K, Cooper J, Deaner A, et al. A single serum glucose measurement predicts adverse outcomes across the whole range of acute coronary syndromes. Heart 2003;89(5):512-6.

[24] Stubbs PJ, Laycock J, Alaghband-Zadeh J, et al. Circulating stress hormone and insulin concentrations in acute coronary syndromes: identification of insulin resistance on admission. Clin Sci (Lond) 1999;96(6):589-95.

[25] Kim JA, Wei Y, Sowers JR. Role of mitochondrial dysfunction in insulin resistance. Circ Res 2008;102(4):401-14.

[26] Jonassen AK, Sack MN, Mjøs OD, et al. Myocardial protection by insulin at reperfusion requires early administration and is mediated via Akt and p70s6 kinase cell-survival signaling. Circ Res 2001;89(12):1191-8.

[27] Mohanty P, Hamouda W, Garg R, et al. Glucose challenge stimulates reactive oxygen species (ROS) generation by leucocytes. J Clin Endocrinol Metab 2000;85(8):2970-3.

[28] Lemkes BA, Hermanides J, Devries JH, et al. Hyperglycemia: a prothrombotic factor? J Thromb Haemost 2010;8(8):1663-9.

[29] Williams SB, Goldfine AB, Timimi FK, et al. Acute hyperglycemia attenuates endothelium-dependent vasodilation in humans in vivo. Circulation 1998;97(17):1695-701. 